\title{
Pulmonary Hemorrhage
}

National Cancer Institute

\section{Source}

National Cancer Institute. Pulmonary Hemorrhage. NCI Thesaurus. Code C78578.

Bleeding from the lung parenchyma. 